\title{
Building a transgenic sexing strain for genetic control of the Australian sheep blow fly Lucilia cuprina using two lethal effectors
}

Ying Yan ${ }^{1,2}$ and Maxwell J. Scott ${ }^{1 *}$

\begin{abstract}
Background: The sterile insect technique (SIT) has been successfully used in many pest management programs worldwide. Some SIT programs release both sexes due to the lack of genetic sexing strains or efficient sex separation methods but sterile females are ineffective control agents. Transgenic sexing strains (TSS) using the tetracycline-off control system have been developed in a variety of insect pests, from which females die by either of two commonly used lethal effectors: overexpression of the transcription factor tetracycline transactivator (tTA) or ectopic expression of a proapoptotic gene, such as head involution defective (hid). The lethality from tTA overexpression is thought to be due to "transcriptional squelching", while hid causes lethality by induction of apoptosis. This study aims to create and characterize a TSS of Lucilia cuprina, which is a major pest of sheep, by combining both lethal effectors in a single transgenic strain.

Results: Here a stable TSS of L. cuprina (DH6) that carries two lethal effectors was successfully generated, by crossing FL3\#2 which carries a female-specific tTA overexpression cassette, with EF1\#12 which carries a tTAregulated Lshid ${ }^{A l a 2}$ cassette. Females with one copy of the FL3\#2 transgene are viable but up to $99.8 \%$ of homozygous females die at the pupal stage when raised on diet that lacks tetracycline. Additionally, the female lethality of FL3\#2 was partially repressed by supplying tetracycline to the parental generation. With an additional Lshid $^{\text {Ala2 }}$ effector, the female lethality of DH6 is 100\% dominant and cannot be repressed by maternal tetracycline. DH6 females die at the late-larval stage. Several fitness parameters important for mass rearing such as hatching rate, adult emergence and sex ratio were comparable to those of the wild type strain.

Conclusions: Compared to the parental FL3\#2 strain, the DH6 strain shows stronger female lethality and lethality occurs at an earlier stage of development. The combination of two tTA-dependent lethal effectors could improve strain stability under mass rearing and could reduce the risk of resistance in the field if fertile males are released. Our approach could be easily adapted for other pest species for an efficient, safe and sustainable genetic control program.
\end{abstract}

Keywords: Sterile insect technique (SIT), Tetracycline transactivator (tTA), Head involution defective (hid), Genetic pest management

\footnotetext{
* Correspondence: miscott3@ncsu.edu

1 Department of Entomology and Plant Pathology, North Carolina State University, Campus Box 7613, Raleigh, NC 27695-7613, USA

Full list of author information is available at the end of the article
}

(c) The Author(s). 2020 Open Access This is an open access article distributed under the terms of the Creative Commons Attribution IGO License (https://creativecommons.org/licenses/by/3.0/igo/) which permits unrestricted use, distribution, and reproduction in any medium, provided appropriate credit to the original author(s) and the source is given. 


\section{Background}

Genetic control methods like the sterile insect technique (SIT) have been used worldwide to battle insect pests. Some SIT programs release both sexes but sterile females are ineffective control agents since they compete with wild females for mating with sterile males [1, 2]. Additionally, release of sterile fruit fly females can be problematic as "sterile stings" can lead to damaged fruit as a consequence of microbial growth at the site of puncture [3]. To achieve male-only release, transgenic sexing strains (TSS) have been developed in a variety of agricultural pests and human-disease vectors [4]. The general strategy to build a TSS is to incorporate a female-specific (FS) element and a lethal effector into the binary tetracycline-off (Tet-off) system. The FS element can be a promoter/enhancer $[5,6]$ or an alternatively spliced intron which is typically derived from the transformer (tra) sex determination gene [7-9]. In a single-component sexing system, the sex-specific tra intron is inserted within the tetracycline transactivator (tTA) gene such that only the female splice variant encodes functional tTA protein. Expression is driven by a tetracycline operator (tetO)-core enhancer-promoter sequence, thus forming an auto-regulated system as binding of tTA to tetO enhances tTA expression. Very high levels of tTA are lethal, possibly due to "transcriptional squelching" and/or interference with ubiquitindependent proteolysis $[7,10]$. In a two-component sexing system, a pro-apoptotic gene such as head involution defective (hid) is driven by the tetO-core enhancerpromoter (effector). The tra intron is inserted within the hid gene such that only the female transcript encodes a functional HID protein. A gene promoter that is mostly active in early embryos is used to drive tTA expression (driver). Binding of tTA to tetO activates hid expression causing female embryo lethality due to high levels of apoptosis $[9,11,12]$. For both systems, only females die when the tetracycline is absent from the diet. Females are fully viable and fertile if tetracycline is added to the insect diet as the antibiotic inhibits binding of tTA to tetO [7, 9-13]. Consequently, the TSS can be maintained in the SIT factory by supplementing the mass rearing diet with tetracycline.

The Australian sheep blow fly Lucilia cuprina, is a major pest of sheep and causes considerable economic loss in Australia and New Zealand [14, 15]. SIT was used to successfully eradicate the New World screwworm Cochliomyia hominivorax, a blow fly that is related to $L$. cuprina, from North and Central American over a 50year program [16]. This was regarded as a significant achievement in insect pest management history [17]. Consequently, genetic control methods were proposed for the control of L. cuprina [18]. L. cuprina TSSs were initially developed using the tTA overexpression system with sex-specificity achieved using the first intron from the C. hominivorax transformer (Chtra) gene [19]. Female lethality was at the late larval/pupal stages [20]. More recently, L. cuprina transgenic embryonic sexing strains (TESS) were established using the twocomponent system, in which the promoters from the $L$. sericata cellularization genes bottleneck (Lsbnk) or nullo were used to drive tTA expression and the effector gene Lshid was interrupted by Chtra intron [12, 21]. Females carrying both driver and effector components died at the embryo stage if given diet that lacked tetracycline. The gene constructs evaluated in L. cuprina were also used to make $C$. hominivorax TSS and the most efficient strains are currently being evaluated for potential field application [12, 20, 22, 23].

Although successful in the laboratory at a small scale, the efficacies of the TSS are subjected to genetic mutations that could hinder the function of a lethal effector. For a Tet-off female lethality system, spontaneous mutations were calculated to occur in the effector genes at a 1 in a million frequency [24]. Currently, more than 15 million sterile $C$. hominivorax are released per week along the Panama-Colombia border, to prevent the reinvasion of $C$. hominivorax from South America [17]. Breakdown of the TSS during mass rearing due to genetic mutation could lead to the release of females. This would be particularly problematic if the radiation step is omitted, which would produce some savings for the program [23]. Further, release of fertile males carrying a single dominant female lethal gene is predicted from modeling to be more efficient than $\operatorname{SIT}[6,25,26]$. This is mostly because the male offspring of the released males could mate with wild females and pass on the dominant female lethal gene to half of their offspring. However, release of fertile males with a single effector could also fail in the field due to preexisting genetic alleles in the targeted population that provide resistance to the lethal mechanism [27]. The tTA overexpression system is sensitive to the genetic background of the population [23, 28]. Similar concerns apply to the use of insecticides. Indeed, pre-existing alleles associated with resistance to malathion were found in $L$. cuprina [29]. Thus, development of TSS with multiple lethal effectors or redundant lethal systems would be very advantageous for an efficient, safe and sustainable genetic control program $[24,30]$. In the present study, two lethal effectors from the single and two-component systems, were combined in a single transgenic strain of L. cuprina. Specifically, the aims of this study were to determine if it is possible to breed a stable homozygous strain that carries the two lethal effectors, and if such strain could enhance the lethal effect and kill females at an earlier developmental stage compared to the parental strain with the single component system. 


\section{Results}

A TSS carrying the two-lethal effectors showed dominant female lethality

To build a L. cuprina TSS with the two lethal effectors, the female-lethal (FL) strain FL3\#2 that carries a sexspecific tTA overexpression cassette [20] and an effector strain EF1\#12 that carries a sex-specific Lshid ${ }^{\text {Ala2 }}$ cassette [12], were selected for crossing and breeding (Fig. 1a). A double homozygous (DH) strain DH6 was successfully generated by screening the wandering third instar larvae based on the fluorescence intensity of the ZsGreen and DsRed whole body marker genes (Fig. 1b). DH6 was stably maintained in the lab on diet supplemented with tetracycline $(100 \mu \mathrm{g} / \mathrm{mL})$ for at least 3 years. On tetracycline, the adult emergence ratio (percentage of pupae that develop into adults) was 86.2, which is comparable to the parental FL3\#2 line and DH strains developed previously with embryo tTA driver lines (Table 1). Further $48.4 \%$ of the adults were female, showing that females are fully viable on diet with tetracycline.

When raised on diet without tetracycline, we previously found that females with one copy of FL3\#2 were viable but $99.9 \%$ of females with two copies of the transgene died at the pupal stage [20]. After several years in culture, we tested FL3\#2 again for female lethality and similar results were obtained (Table 1 ), which suggested that the killing efficiency of tTA overexpression is stable in this line. When raised in the absence of tetracycline,
$100 \%$ of heterozygous DH6 females with one copy of each transgene died (Fig. 2, Table 1). Thus, the lethal effect was largely enhanced when compared to that of FL3\#2 (Table 1). Additionally, it appears that heterozygous females died at a larval stage as most pupae emerged into males $(84.0 \%$, Table 1$)$.

\section{The female lethality of the TSS carrying the two lethal} effectors cannot be inhibited by maternal tetracycline The rearing and female killing efficiencies of FL3\#2 and DH6 were compared under different tetracycline feeding regimens. In all experiments, the larvae of the parental generation were raised on diet supplemented with a high dose of tetracycline $(100 \mu \mathrm{g} / \mathrm{mL})$, then 8 pairs of adults were crossed in a rearing container for each test. These adults were supplied with water that was supplemented with tetracycline $(100 \mu \mathrm{g} / \mathrm{mL})(+\mathrm{W})$ or with water that lacked tetracycline $(-\mathrm{W})$. Their offspring were reared on ground meat with $(+M)$ or without $(-M)$ tetracycline $(100 \mu \mathrm{g} / \mathrm{g})$. Firstly, females of FL3\#2 and DH6 were fully viable and produced similar number of offspring if the parental generation and their larval offspring were fed diet that contained high levels of tetracycline (Fig. 3a, b, $+\mathrm{W} /+\mathrm{M})$. When the parental generation and their offspring were raised on larval diet that had no tetracycline, FL3\#2 produced few, if any, female adults (average $0.7 \pm$ 0.4) while DH6 produced none (Fig. 3a, b, -W/-M). However, under such conditions the fecundity of DH6 after the first egg laying was much less than the parental

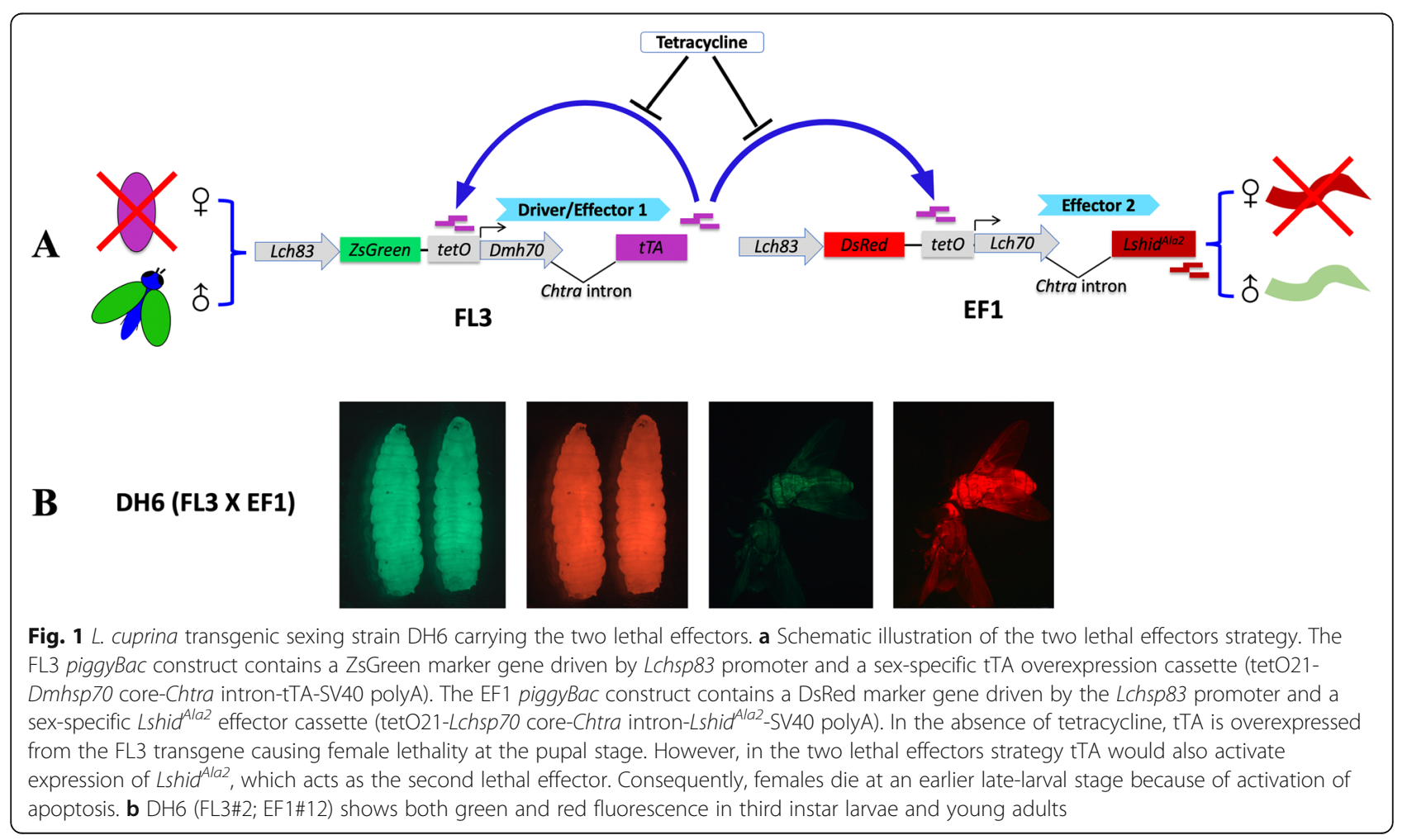


Table 1 Rearing efficiency and female lethality of L. cuprina TSS

\begin{tabular}{|c|c|c|c|c|c|c|c|c|}
\hline TSS & Condition & Tet $^{\mathrm{a}}$ & \#Pupae & \#Male & \#Female & \#Adult & $\mathrm{AER}^{\mathrm{b}}$ & $\%$ Male \\
\hline \multirow[t]{4}{*}{$\overline{F L 3 \# 2^{C}}$} & Heterozygous & - & 2098 & 644 & 735 & 1379 & 65.7 & $46.7 \%$ \\
\hline & & + & 2468 & 1068 & 1048 & 2116 & 85.1 & $50.5 \%$ \\
\hline & Homozygous & - & 2387 & 1029 & 1 & 1030 & 43.1 & $99.9 \%$ \\
\hline & & + & 1647 & 672 & 701 & 1373 & 83.3 & $49.0 \%$ \\
\hline \multirow[t]{2}{*}{$\mathrm{FL} \# 2^{\mathrm{d}}$} & Homozygous & - & 1736 & 881 & 2 & 883 & 50.9 & $99.8 \%$ \\
\hline & & + & 1562 & 629 & 685 & 1314 & 84.1 & $47.9 \%$ \\
\hline \multirow[t]{4}{*}{$\mathrm{DH}^{\mathrm{d}}$ (FL3\#2; EF1\#12) } & Heterozygous & - & 1717 & 1383 & 0 & 1383 & 80.5 & $100 \%$ \\
\hline & Homozygous & - & 427 & 270 & 0 & 270 & 63.2 & $100 \%$ \\
\hline & & $++/-$ & 1421 & 885 & 0 & 885 & 62.3 & $100 \%$ \\
\hline & & + & 1611 & 719 & 669 & 1388 & 86.2 & $51.8 \%$ \\
\hline \multirow[t]{3}{*}{$\mathrm{DH} 1^{\mathrm{e}}$ (DR2\#6; EF1\#12) } & Heterozygous & - & 1091 & 916 & 0 & 916 & 84 & $100 \%$ \\
\hline & Homozygous & $+/-$ & 1054 & 958 & 0 & 958 & 90 & $100 \%$ \\
\hline & & + & 2719 & 1284 & 1234 & 2518 & 92.6 & $51.0 \%$ \\
\hline \multirow[t]{3}{*}{$\mathrm{DH} 2^{\mathrm{e}}$ (DR2\#6; EF3E) } & Heterozygous & - & 1252 & 1099 & 0 & 1099 & 87.8 & $100 \%$ \\
\hline & Homozygous & $+/-$ & 694 & 594 & 0 & 594 & 85.6 & $100 \%$ \\
\hline & & + & 1724 & 784 & 738 & 1522 & 88.3 & $51.5 \%$ \\
\hline \multirow[t]{3}{*}{ DH3 ${ }^{f}$ (DR3\#2; EF3E) } & Heterozygous & - & 1082 & 771 & 0 & 771 & 71.3 & $100 \%$ \\
\hline & Homozygous & $+/-$ & 1158 & 981 & 0 & 981 & 84.7 & $100 \%$ \\
\hline & & + & 1949 & 838 & 810 & 1648 & 84.6 & $50.8 \%$ \\
\hline \multirow[t]{3}{*}{$\mathrm{DH} 4^{\mathrm{f}}$ (DR3\#4; EF1\#12) } & Heterozygous & - & 2398 & 1690 & 30 & 1720 & 71.7 & $98.3 \%$ \\
\hline & Homozygous & $+/-$ & 953 & 801 & 0 & 801 & 84.1 & $100 \%$ \\
\hline & & + & 2284 & 1039 & 1008 & 2047 & 89.6 & $50.8 \%$ \\
\hline \multirow[t]{3}{*}{$\mathrm{DH}^{\mathrm{f}}$ (DR5\#4; EF1\#12) } & Heterozygous & - & 1271 & 1132 & 0 & 1132 & 89.1 & $100 \%$ \\
\hline & Homozygous & - & 660 & 561 & 0 & 561 & 85 & $100 \%$ \\
\hline & & + & 2162 & 981 & 881 & 1862 & 86.1 & $52.7 \%$ \\
\hline
\end{tabular}

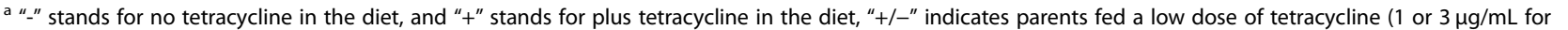
the first 2 days), "++/" indicates a high dose of tetracycline $(100 \mu \mathrm{g} / \mathrm{mL})$ was supplied to the parental adults for the first 8 days but not their progeny that were counted

${ }^{\mathrm{b}} \mathrm{AER}$ stands for adult emergence ratio

'Data from [20]. Eggs were collected up to two times from 10 to 20 pairs of adults

${ }^{\mathrm{d} D a t a}$ from this study, three replicates of 8-pairs per cage

${ }^{\mathrm{e}}$ Data from [12]. For DR2 the bottleneck (bnk) cellularization gene promoter from L. sericata was used to drive expression of tTA. EF3 contains the wild type version of Lshid whereas EF1 has a phosphomutated version called Lshid ${ }^{\text {Ala2 }}$

fData from [31]. The spitting image (spt) gene promoter from L. sericata and the actin5C gene promoter from L. cuprina was used to drive expression of tTA for DR3 and DR5, respectively

wild type (WT) strain with very few eggs produced (data not shown). Consequently, the male production of DH6 $(90.0 \pm 15.3)$ on diet without tetracycline was significantly less than that from diet with tetracycline $(239.7 \pm$ 23.1) $(P<0.001$, one-way ANOVA; Fig. $3 b)$. In a previously described $L$. cuprina TSS (DH4), females were sterile unless fed a limiting dose of tetracycline $(3 \mu \mathrm{g} /$ $\mathrm{mL}$, first 2 days after eclosion) [31]. This appeared to be due to low level expression of tTA in the ovaries activating the effector gene. We suspected a similar situation in DH6, as the tTA autoregulation system could be engaged when tetracycline was absent from the adult female diet. If so, the accumulation of tTA in the ovary would activate the Lshid ${ }^{\text {Ala2 }}$ effector, which could lead to female sterility.

To restore the female fertility and increase the male production of DH6, different doses of tetracycline were fed to the parental generation. We tested three different limiting tetracycline doses; $3 \mu \mathrm{g} / \mathrm{mL}$ for the first 2 days, $3 \mu \mathrm{g} / \mathrm{mL}$ for the first 8 days and $10 \mu \mathrm{g} / \mathrm{mL}$ for the first 8 days after emergence. Egg laying is typically at day 8 . However, with each of these tetracycline feeding regimens, DH6 females were sterile (data not shown). Consequently, we supplied DH6 adults high levels of tetracycline $(100 \mu \mathrm{g} / \mathrm{mL})$ for the first 8 days. By doing so, fertility was fully restored and male production was 


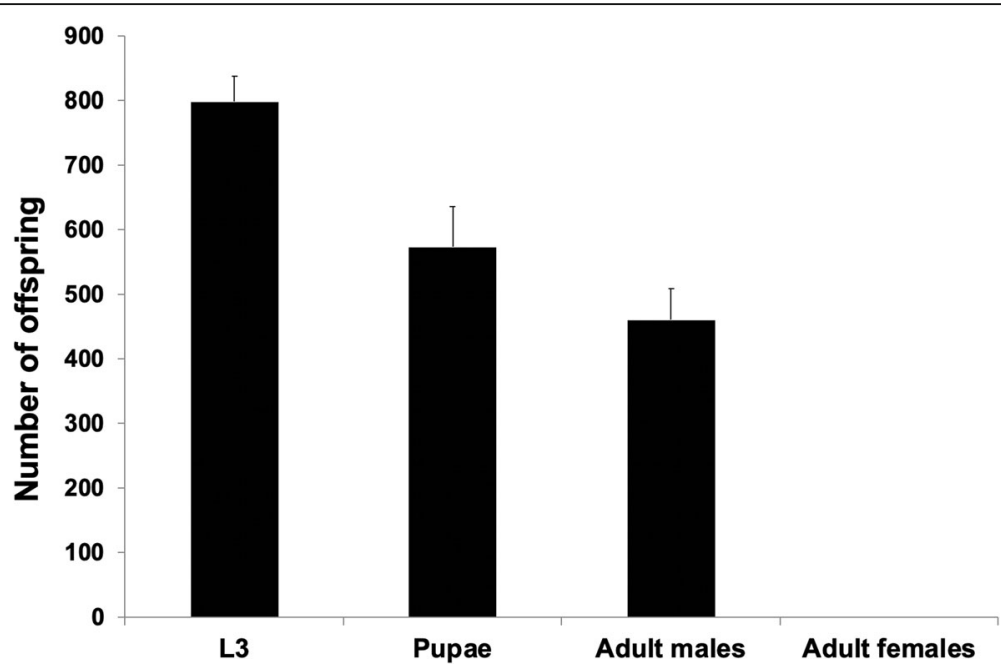

Fig. 2 Female-specific lethality of DH6 with one copy of each transgene. Eight homozygous DH6 males were crossed with eight WT virgin females and their offspring raised on diet without tetracycline. The number of wandering third instar larvae (L3), pupae and adult male and female offspring from each cross were counted. Each experiment was performed three times. Mean \pm standard deviation are shown

$223.7 \pm 14.9$ (Fig. $3 \mathrm{~b},+\mathrm{W} /-\mathrm{M}$ ), which is comparable to that obtained with tetracycline supplied in the adult and larval diets $(+\mathrm{W} /+\mathrm{M})$. Importantly, the high dose of tetracycline supplied to parents was not sufficient to inhibit activation of the lethal systems in DH6 as 100\% of the female offspring died (Fig. $3 b,+W /-M)$. On the other hand, FL3\#2 produced $98.0 \pm 24.0$ females (Fig. 3a, $+\mathrm{W} /-\mathrm{M})$, which was significantly higher than that from the non-tetracycline condition $(P=0.001)$. This suggested that maternal tetracycline inhibited tTA overexpression in some FL3\#2 females. FL3\#2 and DH6 females were rescued by adding tetracycline to the larval diet (Fig. 3a, b, $-W /+M$ ), which indicated that females were not dying at the embryo stage or early larval stage.

To further verify the effect of maternal tetracycline as well as the stage of lethality, 1000 eggs were collected from the homozygous FL3\#2 and DH6 and the number of hatched first instar larvae, third instar larvae, pupae and adult males and females were counted. On diet without tetracycline, less than half of FL3\#2 pupae emerged as males (42.3\%), while most of DH6 pupae emerged into males (88.3\%, Fig. 4). This is consistent with previous observations that FL3\#2 females die at the pupal stage but indicates that DH6 females died at an
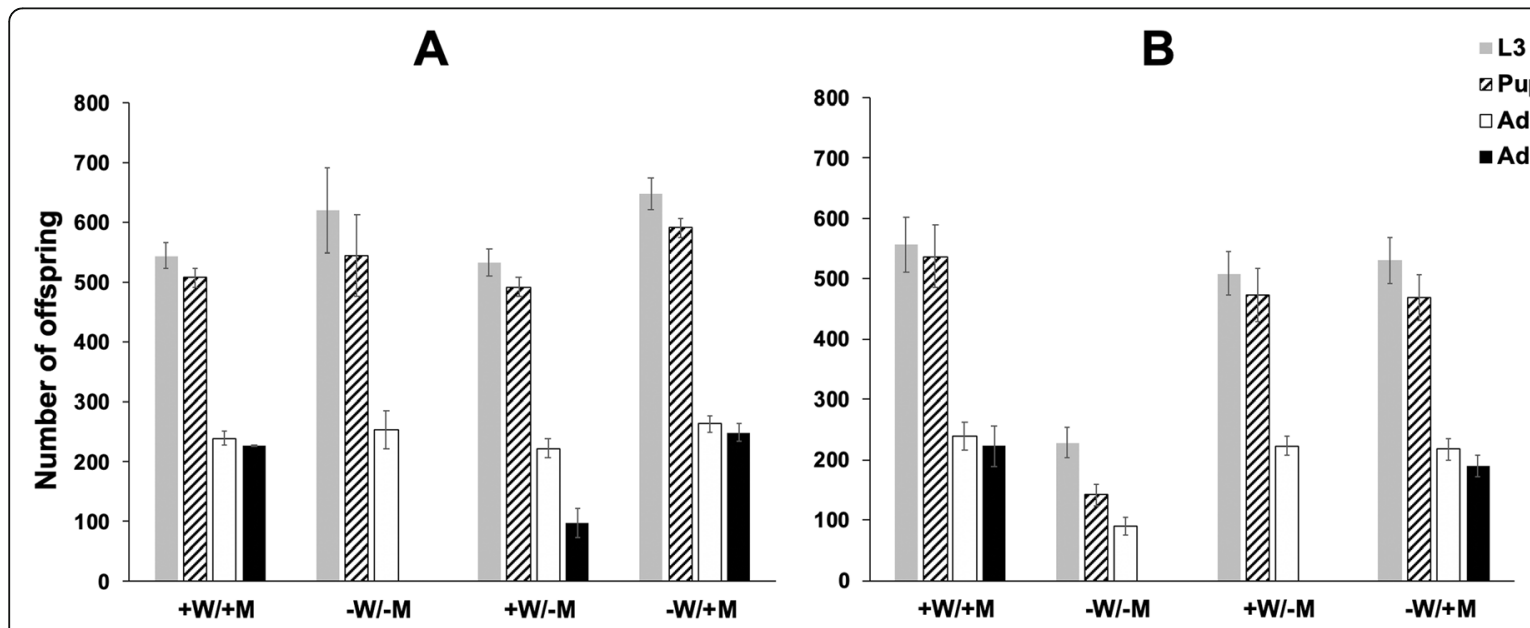

Fig. 3 Female-specific lethality of FL3\#2 (a) and DH6 (b) under different tetracycline feeding regimens. Containers were set with eight pairs of adults and the number of third instar (L3), pupae and adult male and female offspring were counted. $+W$ : parental generation fed water with $100 \mathrm{\mu g} / \mathrm{mL}$ tetracycline from day 1 (D1) to D8; -W: parental generation fed water without tetracycline from D1 to D8; +M: ground meat (larval diet) with $100 \mathrm{\mu g} / \mathrm{g}$ tetracycline; $-\mathrm{M}$ : meat without tetracycline. Each experiment was performed three times. Mean \pm standard deviation are shown 


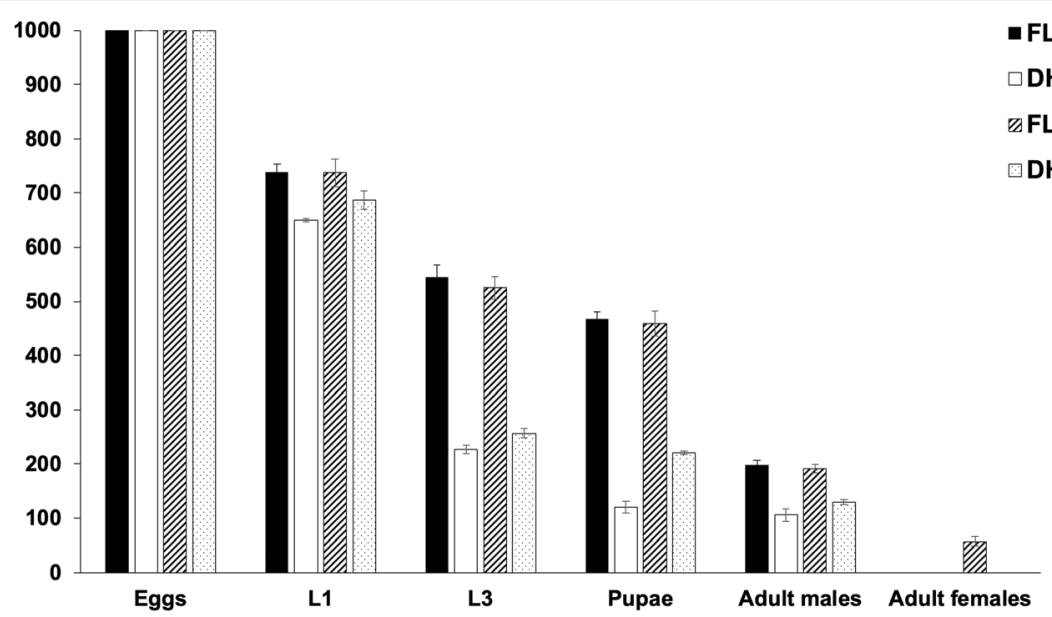

Fig. 4 Staged lethality of FL3\#2 and DH6 under different tetracycline feeding regimens. 1000 embryos were collected and the numbers of first instar (L1), third instar larvae (L3), pupae, adult males and adult females were recorded. Each experiment was performed three times. Mean \pm standard deviation are shown

earlier stage. When parents but not their offspring were fed a high level of tetracycline, FL3\#2 produced $57.3 \pm$ 8.4 female adults out of 1000 eggs while DH6 produced none (Fig. 4), which confirmed that the female lethality of DH6 cannot be inhibited by maternal tetracycline. A similar reduction from first instar to third instar in DH6 under either condition (35.0\% for $-\mathrm{W} /-\mathrm{M}, 37.4 \%$ for $+\mathrm{W} /-\mathrm{M})$ suggested that most, if not all, females survived to the third instar stage. Without tetracycline, half of DH6 third instar developed into pupae (52.8\%), while most of the third instar larvae developed into pupae (86.1\%) when a high level of tetracycline was supplied to the parental generation (Fig. 4). This suggested that maternal tetracycline shifted the major lethal stage from the third instar to pupae in DH6.

\section{Evaluation of some fitness characteristics important for mass-rearing}

To evaluate the potential of the DH6 for mass-rearing in a factory, several fitness characteristics were measured and compared to the parental EF1\#12 and FL3\#2 strains and also to WT. For embryo hatching (Fig. 5a), there were no significant differences between the transgenic lines, but there were significant differences between the transgenic lines and the WT $(P<0.05$, one-way ANOVA). The egg/pupae survival of DH6 was significantly lower than that from WT $(P<0.001)$, EF1\#12 $(P=0.015)$ and FL3\#2 $(P<0.001)$ (one-way ANOVA; Fig. 5b). This could indicate that basal expression of the two lethal effectors is reducing viability. The adult emergence ratio (Fig. 5c) and adult sex ratio (Fig. 5d) were not significantly different between any of the transgenic lines and the WT.

For application to the SIT, it is important that the TSS be reared efficiently with tetracycline diet in the factory, but also generate the necessary number of males for field release when raised on diet that lacks tetracycline. Consequently, we next further compared the rearing efficiency of DH6 with other TSS that have been generated in earlier studies. Specifically, the TSSs DH1, DH2, DH3, DH4, DH5 and FL3\#2, one of the parental strains for DH6. These two component strains combined a driver that expressed tTA in embryos with a tetO-hid effector that was activated by tTA. The gene constructs are shown schematically in Additional file 1, Fig. S1. DH1 contains a $L s b n k$-tTA embryo driver (Lsbnk is the $b n k$ gene promoter from $L$. sericata) combined with a EF1 effector. DH2 contains the same driver but an EF3 effector (similar to EF1 but contains the wild type version of Lshid) [12]. DH3 contains a Lsspt-tTA driver (Lsspt is the spitting image gene promoter from $L$. sericata) that has activity throughout development combined with a EF3 effector, whereas DH4 contains the same driver and a EF1 effector [31]. DH5 contains Lcact5C-tTA driver (Lcact5C is the actin $5 C$ gene promoter from L. cuprina) that has activity throughout development and a EF1 effector [31]. From 24 pairs of flies on tetracycline (Table 1, Additional File 1, Fig. S1), FL3\#2 produced the lowest number of adults (1314) and DH1 produced highest number of adults (2518). On diet without tetracycline or a low dose feeding regimen, DH6 produced the lowest number of males (270) and DH3 the highest (981). The number of male offspring from DH6 was 885 with a high concentration of tetracycline supplied only to the parental generation (Table 1). Thus, under such conditions the male production of DH6 is comparable to the best of the previously made TSS. The adult eclosion ratio (AER) in the release generation is also an important factor as sterile pupae are the end product from the mass rearing factory. The DH6 AER was 62.3 when 


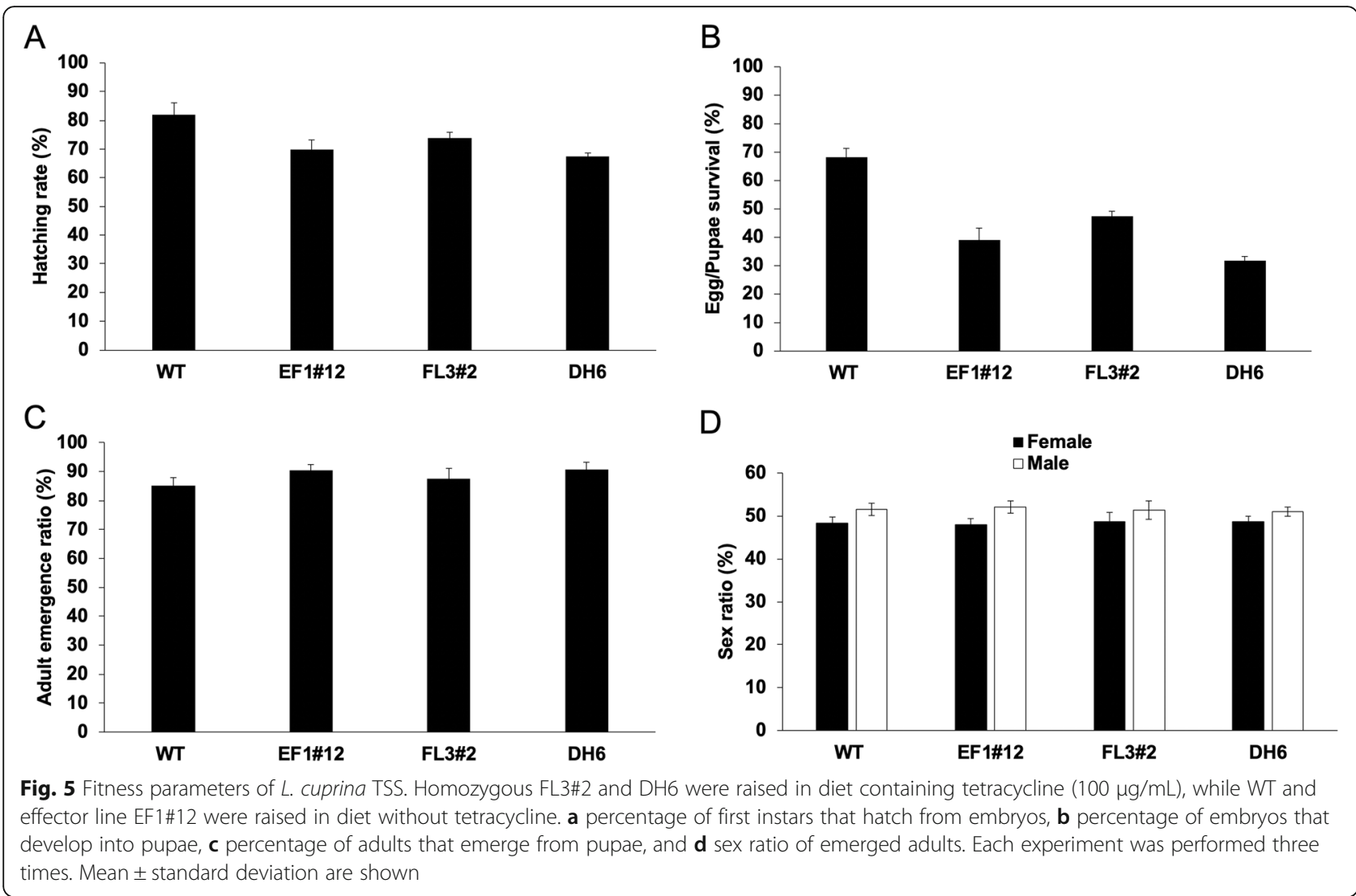

tetracycline was only supplied to the parental generation. This was significantly less than the AER for other TSS such as DH1 (AER $\left.=90 ; P<0.001, X^{2}=259.03\right)$ as well as WT.

\section{Discussion}

The SIT has been successfully used to control a number of significant insect pests, including the eradication of invasive pests. For example, C. hominivorax was recently eradicated from the Florida Keys within a few months after detection [32]. This was achieved through successive releases of radiation sterilized males and females produced at the mass rearing facility in Panama and flown to Florida. Similarly, the SIT was used to eradicate an outbreak of $C$. hominivorax in Libya in the 1980s [33]. In addition to the SIT, eradication was achieved through the coordinated implementation of other pest control measures such as the use of insecticides to treat animals with infestations.

The DH6 TSS obtained in this study offers several advantages for an SIT program. First, a male-only release would increase the efficiency and costeffectiveness of a population suppression program [34, 35]. Second, as female lethality cannot be inhibited by maternal tetracycline, any adult females that accidently escape from the SIT facility would not be able to produce female offspring. Third, as the lethal effect was dominant, males could be released without radiation treatment, which could potentially increase the fitness of released insects [36] and reduce the capital costs of the SIT facility [18]. Regarding a fertile male release, we [12] and others [37] previously considered that two component driver-effector systems would only be used for sterile release programs as the transgenes would independently segregate after mating. However, a recent modeling study has shown that a release of fertile males with driver and effector transgenes on different chromosomes could be effective for population suppression [38]. These three advantages are shared with other L. cuprina TSS (DH1 and DH5) made in earlier studies [12, 31]. One unique advantage of DH6 is that since both tTA and Lshid $^{\text {Ala2 }}$ contain the sex-specific Chtra intron, only females would produce the effector proteins, which could improve male fitness compared to other TSS that use strong tTA driver lines. Another unique advantage of DH6 is the combination of two tTAdependent lethal effectors, which would be predicted to improve strain stability under mass rearing and could reduce the risk of resistance in the field if fertile males are released. The last feature is very 
important in large scale long-term suppression programs $[24,30]$.

For a fertile release, resistance could emerge due to standing genetic variation in the targeted population [28]. For example, we recently found genetic background had a significant impact on the level of survival of female $D$. melanogaster that carried one copy of a female-specific tTA overexpression transgene [28]. Under mass rearing conditions, a TSS would be predicted to acquire random new mutations. It is possible that these mutations would provide a mechanism of resistance to the tTA overexpression system. For example, low tTA protein accumulation due to mutation in the enhancer/promoter or tTA coding sequence. The addition of the tetO-hid second lethal system would improve strain stability as the level of tTA protein required to activate hid is less than needed to cause dominant lethality based on tTA overexpression.

Despite the advantages mentioned above, DH6 does come with some limitations that could potentially hinder its practical application. First, female fertility was poor unless high levels of tetracycline were supplied in the adult diet, adding to the cost of rearing. Second, the adult eclosion ratio on diet without tetracycline was low compared to TSS made previously. This will add to the cost of the SIT program if a significant percentage of males in the release generation consume larval diet but do not develop into adults. Third, DH6 would provide little savings in larval diet costs as females die either at late-larval stage without tetracycline, or at pupae stage with maternal tetracycline. Fourth, as both DH6 lethal effectors are dependent on tTA, a complete loss-of-function mutation in the tTA gene would shut down the expression of both tTA and hid, thus females would be viable and fertile in the absence of tetracycline. This could be particularly problematic in a fertile release program. For this reason, it has been suggested that TSS be developed carrying two completely independent lethal systems. For example, use the quinic acidregulated $Q$ system to control male sterility [30], or temperature-system lethal [24], in addition to a tetracycline-repressible female lethal system.

If fertile DH6 males are released, transgenic male larvae will survive and develop in the wounds in live sheep and in dead animals. The latter is because, unlike C. hominivorax, L. cuprina is not an obligate parasite. The presence of live transgenic larvae in sheep may not be acceptable to farmers. In addition, during a suppression program we would anticipate that farmers would be particularly vigilant for flystrike and treat infested sheep with insecticides, as was done during the screwworm eradication program [16, 17].
The insecticide treatment would kill the male larvae, which would decrease the advantage of a fertile release program compared to releasing radiation sterilized males. For use in Australia, it would be desirable to backcross DH6 to a local strain of L. cuprina for at least 5 generations. The strain would then need to be made homozygous again for the two transgenes. Additional fitness tests for traits important for mass rearing (e.g. fecundity, egg hatch) and performance in the field (e.g. male competitiveness) would then need to be performed, as we have done previously for transgenic screwworm strains [23]. Lastly, although DH6 could be used for population suppression, each transgene could persist separately in the remaining population unless the gene has a fitness cost. There could be a negative fitness cost due to low level gene expression in females, expression of the marker gene or impact on expression of genes located near the transgene. Nevertheless, it could be more challenging to obtain regulatory approval for a field trial compared to a strain with a single dominant lethal transgene, which would not be expected to persist in the field for long after release as was observed in Brazil [39]. If so, it would be advantageous to combine the two effectors into a single construct.

Late-stage female lethality could be a beneficial for other pest species such as mosquito disease vectors that have strong density-dependent effects, since the larvae carrying lethal transgene(s) would compete for limited resources and thus reduce the survival of their wild counterparts $[10,40]$. The two lethal effector approach described in this study could be applied to mosquitoes. tTA overexpression strains [10] and effector strains using the pro-apoptotic michelob-x gene [41] have been developed for Aedes aegypti. Combining these strains for the two-lethal effector would kill both sexes since the sex-specific intron is not present in these systems. The Chtra intron used in this study to achieve female-specific lethality would likely not be functional in mosquitoes as they appear to lack an ortholog of the transformer gene [42]. Alternatively, the female-specifically spliced intron from $A$. aegypti Actin- 4 gene could be considered, which was successfully used to regulate female-specific gene expression in this species [41]. In addition to applications in pest management, the strategy of the two-effector system can also be used when strong and conditional gene expression is needed. For example, we previously described transgenic $L$. sericata larvae that produce and secrete a human platelet derived growth factor (hPDGF) for enhanced maggot debridement therapy [43]. Combination of bi-sex tTA overexpression and the tetO-hPDGF transgene could potentially increase the larval secretion of hPDGF, and also reduce the 
clinic risks because the insects are expected to die at the pupal stage after medical use. One disadvantage of this approach is that it is possible that high levels of tTA could weaken the maggots and reduce their effectiveness for debridement.

\section{Conclusions}

Here a stable TSS of L. cuprina (DH6) that carries two lethal effectors was generated. DH6 contains a tTA overexpression cassette and an additional Lshi$d^{\text {Ala } 2}$ effector cassette. The former is thought to be lethal due to "transcriptional squelching" or interference with ubiquitin-dependent protein degradation while lethality of the latter is due to widespread apoptosis. Both tTA and Lshid ${ }^{\text {Ala2 }}$ genes are interrupted by a sex-specific intron so only females die. The female lethality of DH6 was dominant and cannot be suppressed by maternal tetracycline. We argue that combining two different lethal effectors in a single SIT strain would increase stability during mass rearing and reduce the emergence of resistance in the field in a fertile male release program. The two lethal effector strategy could be applied to other pest species such as mosquito disease vectors and could be advantageous when high levels of conditional expression of a protein is required such as for production of wound healing factors by germ-free L. sericata maggots.

\section{Methods}

\section{Fly rearing and double homozygous line breeding}

The LA07 WT strain of L. cuprina was maintained as previously described [20]. In brief, adults were kept in mesh cages at $22{ }^{\circ} \mathrm{C}$ and fed a sugar/water/protein biscuit diet. Larvae were raised on $93 \%$ ground beef at $27^{\circ} \mathrm{C}$ and pupae were kept in a $27^{\circ} \mathrm{C}$ incubator until eclosion. Homozygous virgin females from EF1\#12 were crossed with homozygous males from FL3\#2 to generate double heterozygous femalespecific lethal strain. The double heterozygous strain was inbred and their progeny screened to select only individuals homozygous (DH6) for both EF1 and FL3 transgenes by epifluorescence microscopy based on fluorescence intensity of ZsGreen and DsRed. Prior to testing, DH6 were maintained on diet supplemented with $100 \mu \mathrm{g} / \mathrm{mL}$ tetracycline for at least 5 generations with no loss of green or red fluorescence intensity, confirming the accuracy of the initial selection of homozygous larvae.

\section{Female lethality assessments and tetracycline feeding tests}

To assess female lethality in a double heterozygous condition, 8 newly emerged males from DH6 and 8 newly emerged virgin females from WT were put in one bottle and kept on tetracycline-free adult diet for 8 days. Then embryos of $24 \mathrm{~h}$ egg lay intervals were reared on tetracycline-free raw ground beef (93\% protein and $7 \%$ fat) and the number of third instar larvae, pupae and adult male and female were counted. Female lethality in a double homozygous condition was addressed in the same way. To test if the lethality is repressible, tetracycline $(100 \mu \mathrm{g} / \mathrm{mL})$ was added to water fed to the adults and to the raw ground beef fed to the larvae. To verify the lethal stage, embryos were collected on ground beef then transferred to moist black filter paper in a Petri dish and counted. Each Petri dish held 1000 embryos and was incubated at $27^{\circ} \mathrm{C}$ overnight. The following day, unhatched eggs were scored and the number of first instar larvae were calculated as (1000 - number of unhatched eggs). Then the first instar larvae were transferred to meat, and the number of 3rd instar larvae, pupae, adult males and females were recorded afterwards. All lethality tests were done in triplicate.

\section{Fitness tests}

Fitness tests were performed for the WT and transgenic lines as described previously for C. hominivorax [23]. Homozygous FL3\#2 and DH6 were tested in diet containing tetracycline $(100 \mu \mathrm{g} / \mathrm{mL})$, while WT and effector line EF1\#12 were tested in diet without tetracycline. All tests were replicated at least three times unless otherwise indicated. For hatching rate, 1000 eggs were collected as described above and the number of hatched larvae were scored and the percentage egg hatch was calculated. The hatched larvae were then transferred to meat and developed into pupae. The number of pupae were counted and the egg/pupae survival rate was calculated. The adult emergence ratio was calculated as [number of adults emerged/ number of pupae] $\mathrm{X}$ 100. Then the pupae were placed in a closed container and adults were allowed to emerge for 5 days after the emergence of the first insect. Males and females were counted and percentage of emergence and sex ratio calculated.

\section{Statistical analysis}

Statistical analysis was performed using SigmaPlot 12.5. The differences in offspring number from different tetracycline feeding regimen for each TSS, or the differences in fitness parameters from different transgenic lines and WT, were analyzed using one-way ANOVA and means were separated using Holm-Sidak method. Differences in the adult eclosion ratio between strains were determined using a $x^{2}$ test. 


\section{Supplementary Information}

The online version contains supplementary material available at https://doi. org/10.1186/s12863-020-00947-y.

Additional file 1: Fig. S1. Schematic illustration of gene constructs and female lethality of $L$. cuprina transgenic sexing strains. Tetracycline feeding conditions were as follows: "-" stands for no tetracycline in the diet, "+" stands for plus tetracycline in the diet, "+/--" indicates parents fed a low dose of tetracycline ( 1 or $3 \mu \mathrm{g} / \mathrm{mL}$ for the first two days), and "++/-" indicates a high dose of tetracycline $(100 \mu \mathrm{g} / \mathrm{mL})$ was supplied to the parental adults for the first eight days but not their progeny that were counted. AER stands for adult emergence ratio. The data for FL3\#2 were collected up to two times from 10 to 20 pairs of adults, and all other data were from three replicates of 8-pairs per cage. A. FL3 was a tTA autoregulated construct with the female-specifically spliced intron from the C. hominivorax (Chtra) transformer gene. The data shown is from [20]. B. Double homozygous (DH) strain DH1 contains the driver-2 (DR2) gene cassette in which the bottleneck (bnk) cellularization gene promoter from L. sericata (Lsbnk) was used to drive expression of tTA combined with the effector-1(EF1) gene cassette in which Lshid ${ }^{\text {Ala2 }}$ contained the Chtra intron. C. DH2 contains DR2 and EF3 in which the wild type version of Lshid was used. The data shown for $\mathrm{DH} 1$ and $\mathrm{DH} 2$ are from [12]. D. DH3 has DR3 in which the spitting image (spt) gene promoter from L. sericata (Lsspt) was used and EF3. E. DH4 combines DR3 and EF1 lines. F. $\mathrm{DH} 5$ contains DR5 in which the actin5C gene promoter from L. cuprina (LC actin5C) was used to drive tTA combined with EF1. The data shown for $\mathrm{DH} 3, \mathrm{DH} 4$ and $\mathrm{DH} 5$ are from [31]. G. DH6 combines FL3\#2 with EF1, and data shown were from this study.

\section{Acknowledgements}

We thank Amy Keeter, Jodie White and Mary Hester for assistance with fly rearing. This study was benefitted from discussions at International Atomic Energy Agency funded meetings for the Coordinated Research Projects; "The Use of Molecular Tools to Improve the Effectiveness of SIT" and "Comparing Rearing Efficiency and Competitiveness of Sterile Male Strains Produced by Genetic, Transgenic or Symbiont-based Technologies".

\section{About this supplement}

This article has been published as part of BMC Genetics Volume 21 Supplement 2, 2020: Comparing rearing efficiency and competitiveness of sterile male strains produced by genetic, transgenic or symbiont-based technologies. The full contents of the supplement are available online at https://bmcgenet. biomedcentral.com/articles/supplements/volume-21-supplement-2.

\section{Authors' contributions}

Y.Y. designed and performed the experiments, analyzed the data and drafted the manuscript. M.J.S. conceived of the study, participated in its design and drafted the manuscript. All authors read and approved the final manuscript.

\section{Funding}

Funding is gratefully acknowledged from specific cooperative agreements between the USDA-ARS and NCSU and the Panama-United States Commission for the Eradication and Prevention of Screwworm (COPEG) to MJS. Publication costs are funded by the Joint FAO/IAEA Division of Nuclear Techniques in Food and Agriculture, IAEA (CRP No.: D4.20.16) Vienna, Austria. The funding bodies played no role in the design of the study and collection, analysis, and interpretation of data and in writing the manuscript.

\section{Availability of data and materials}

All data generated or analysed during this study are included in this published article.

\section{Ethics approval and consent to participate}

"Not applicable" as this study did not involve any animal or human data or tissue.

\section{Consent for publication}

"Not applicable".

\section{Competing interests}

The authors declare that they have no competing interests.

\section{Author details}

${ }^{1}$ Department of Entomology and Plant Pathology, North Carolina State University, Campus Box 7613, Raleigh, NC 27695-7613, USA. ²Department of Insect Biotechnology in Plant Protection, Justus-Liebig-University Giessen, Institute for Insect Biotechnology, Winchesterstraße 2, 35394 Giessen, Germany.

Published online: 18 December 2020

References

1. Knipling EF. Sterile-male method of population control. Science. 1959;130: 902-4.

2. Franz G. Genetic sexing strains in Mediterranean fruit Fly, an example for other species amenable to large-scale rearing for the sterile insect technique. In: Dyck VA, Hendrichs J, Robinson A, editors. Sterile Insect Technique. Dordrecht: Springer; 2005. p. 427-51.

3. Hendrichs J, Franz G, Rendon P. Increased effectiveness and applicability of the sterile insect technique through male-only releases for control of Mediterranean fruit-flies during fruiting seasons. J Appl Entomol. 1995; 119(5):371-7.

4. Harvey-Samuel T, Ant T, Alphey L. Towards the genetic control of invasive species. Biol Invasions. 2017;19:1683-703.

5. Heinrich JC, Scott MJ. A repressible female-specific lethal genetic system for making transgenic insect strains suitable for a sterile-release program. Proc Natl Acad Sci U S A. 2000;97:8229-32.

6. Thomas DD, Donnelly CA, Wood RJ, Alphey LS. Insect population control using a dominant, repressible, lethal genetic system. Science. 2000; 287(5462):2474-6.

7. Fu G, Condon KC, Epton MJ, Gong P, Jin L, Condon GC, Morrison NI, Dafa'alla TH, Alphey L. Female-specific insect lethality engineered using alternative splicing. Nat Biotechnol. 2007;25:353e57.

8. Dafa'alla T, Fu G, Alphey L. Use of a regulatory mechanism of sex determination in pest insect control. J Genet. 2010;89(3):301-5.

9. Schetelig MF, Handler AM. A transgenic embryonic sexing system for Anastrepha suspensa (Diptera: Tephritidae). Insect Biochem Mol Biol. 2012;42: 790-5.

10. Phuc H, Andreasen M, Burton R, Vass C, Epton M, Pape G. Late-acting dominant lethal genetic systems and mosquito control. BMC Biol. 2007; 5:11.

11. Ogaugwu CE, Schetelig MF, Wimmer EA. Transgenic sexing system for Ceratitis capitata (Diptera: Tephritidae) based on female-specific embryonic lethality. Insect Biochem Mol Biol. 2013:43:1-8

12. Yan Y, Scott MJ. A transgenic embryonic sexing system for the Australian sheep blow fly Lucilia cuprina. Sci Rep. 2015;5:16090.

13. Gossen M, Bujard $\mathrm{H}$. Tight control of gene expression in mammalian cells by tetracycline-responsive promoters. Proc Natl Acad Sci U S A. 1992;89: 5547-51.

14. Heath AC, Bishop DM. Flystrike in New Zealand: an overview based on a 16 year study, following the introduction and dispersal of the Australian sheep blowfly, Lucilia cuprina Wiedemann (Diptera: Calliphoridae). Vet Parasitol. 2006;137:333-44.

15. Sandeman RM, Levot GW, Heath AC, James PJ, Greeff JC, Scott MJ, Batterham P, Bowles VM. Control of the sheep blowfly in Australia and New Zealand--are we there yet? Int J Parasitol. 2014;44:879-91.

16. Klassen W, Curtis CF. History of the Sterile Insect Technique. In: Dyck VA, Hendrichs J, Robinson AS, editors. Sterile Insect Technique. Principles and Practice in Area-Wide Integrated Pest Management. Dordrecht: Springer; 2005. p. 3-36.

17. Scott MJ, Concha C, Welch JB, Phillips PL, Skoda SR. Research advances in the screwworm eradication program over the past 25 years. Entomol Exp Appl. 2017;164:226-36.

18. Foster GG, Weller GL, James WJ, Paschalidis KM, McKenzie LJ. Advances in sheep blowfly genetic control in Australia. In: Agency IAE, editor. Management of insect pests: nuclear and related molecular and genetic techniques; 1993. p. 299-312.

19. Li F, Vensko SPI, Belikoff EJ, Scott MJ. Conservation and sex-specific splicing of the transformer gene in the Calliphorids Cochliomyia hominivorax, Cochliomyia macellaria and Lucilia sericata. PLoS One. 2013;8:e56303. 
20. Li F, Wantuch HA, Linger RJ, Belikoff EJ, Scott MJ. Transgenic sexing system for genetic control of the Australian sheep blow fly Lucilia cuprina. Insect Biochem Mol Biol. 2014;51:80-8.

21. Yan Y, Williamson ME, Davis RJ, Andere AA, Picard CJ, Scott MJ. Improved transgenic sexing strains for genetic control of the Australian sheep blow fly Lucilia cuprina using embryo-specific gene promoters. Mol Gen Genomics. 2020;295:287-98.

22. Concha C, Yan Y, Arp A, Quilarque E, Sagel A, de León AP, McMillan O, Skoda S, Scott MJ. An early female lethal system of the New World screwworm, Cochliomyia hominivorax, for biotechnology-enhanced SIT in area-wide pest management. BMC Genet. https://doi.org/10.1186/s12863020-00948-x

23. Concha C, Palavesam A, F.D. G, Sagel A, Li F, Osborne JA, Hernandez Y, Pardo T, Quintero G, Vasquez M, Keller GP, Phillips PL, Welch JB, McMillan WO, Skoda SR, Scott MJ. A transgenic male-only strain of the New World screwworm for an improved control program using the sterile insect technique. BMC Biology. 2016;14:72.

24. Handler A. Enhancing the stability and ecological safety of mass-reared transgenic strains for field release by redundant conditional lethality systems. Insect Sci. 2016;23:225-34.

25. Schliekelman P, Gould F. Pest control by the release of insects carrying a female-killing allele on multiple loci. J Econ Entomol. 2000; 93(6):1566-79.

26. Burt A, Deredec A. Self-limiting population genetic control with sex-linked genome editors. Proc Biol Sci. 2018;285:20180776.

27. Alphey N, Bonsall MB, Luke AL. Modeling resistance to genetic control of insects. J Theor Biol. 2011;270:42-55.

28. Knudsen KE, Reid WR, Barbour TM, Bowes LM, Duncan J, Philpott E, Potter S, Scott MJ. Genetic Variation and Potential for Resistance Development to the tTA Overexpression Lethal System in Insects. G3 (Bethesda). 2020;10(4): $1271-81$.

29. Hartley CJ, Newcomb RD, Russell RJ, Yong CG, Stevens JR, Yeates DK, La Salle J, Oakeshott JG. Amplification of DNA from preserved specimens shows blowflies were preadapted for the rapid evolution of insecticide resistance. Proc Natl Acad Sci U S A. 2006;103:8757-62.

30. Eckermann KN, Dippel S, KaramiNejadRanjbar M, Ahmed HM, Curril IM Wimmer EA. Perspective on the combined use of an independent transgenic sexing and a multifactorial reproductive sterility system to avoid resistance development against transgenic sterile insect technique approaches. BMC Genet. 2014;15(Suppl 2):S17.

31. Yan Y, Linger RJ, Scott MJ. Building early-larval sexing systems for genetic control of the Australian sheep blow fly Lucilia cuprina using two constitutive promoters. Sci Rep. 2017;7:2538. https://doi.org/10.1038/s41598017-02763-4.

32. Skoda SR, Phillips PL, Welch JB. Screwworm (Diptera: Calliphoridae) in the United States: response to and elimination of the 2016-2017 outbreak in Florida. J Med Entomol. 2018;55(4):777-86.

33. Lindquist DA, Abusowa M, Hall MJ. The New World screwworm fly in Libya: a review of its introduction and eradication. Med Vet Entomol. 1992;6(1):2-8.

34. McInnis DO, Tam S, Grace C, Miyashita D. Population suppression and sterility rates induced by variable sex-ratio, sterile insect releases of CeratitisCapitata (Diptera, Tephritidae) in Hawaii. Ann Entomol Soc Am. 1994;87(2): 231-40.

35. Rendon P, Mclnnis D, Lance D, Stewart J. Medfly (Diptera: Tephritidae) genetic sexing: large-scale field comparison of males-only and bisexual sterile fly releases in Guatemala. J Econ Entomol. 2004;97:1547-53.

36. Crystal MM. Sterilization of screwworm flies (Diptera: Calliphoridae) with gamma rays: restudy after two decades. J Med Entomol. 1979;15:103-8.

37. Wimmer EA. Innovations: applications of insect transgenesis. Nat Rev Genet. 2003:4(3):225-32.

38. Vella MR, Gould F, Lloyd AL. Mathematical modeling of genetic pest management through female-specific lethality: Is one locus better than two? Preprint at. https://doi.org/10.1101/2020.04.06.028738.

39. Garziera L, Pedrosa MC, de Souza FA, Gomez M, Moreira MB, Virginio JF, Capurro ML, Carvalho DO. Effect of interruption of over-flooding releases of transgenic mosquitoes over wild population of Aedes aegypti: two case studies in Brazil. Entomol Exp Appl. 2017;164(3):327-39.

40. Alphey L. Genetic control of mosquitoes. Annu Rev Entomol. 2014;59: 205-24.
41. Fu G, Lees RS, Nimmo D, Aw D, Jin L, Gray P, Berendonk TU, White-Cooper $\mathrm{H}$, Scaife S, Kim Phuc H, Marinotti O, Jasinskiene N, James AA, Alphey L. Female-specific flightless phenotype for mosquito control. Proc Natl Acad Sci U S A. 2010;107(10):4550-4.

42. Geuverink E, Beukeboom LW. Phylogenetic distribution and evolutionary dynamics of the sex determination genes doublesex and transformer in insects. Sexual Development. 2014;8(1-3):38-49.

43. Linger RJ, Belikoff EJ, Yan Y, Li F, Wantuch HA, Fitzsimons HL, Scott MJ. Towards next generation maggot debridement therapy: transgenic Lucilia sericata larvae that produce and secrete a human growthfactor. BMC Biotechnol. 2016;16:1-12

\section{Publisher's Note}

Springer Nature remains neutral with regard to jurisdictional claims in published maps and institutional affiliations.
Ready to submit your research? Choose BMC and benefit from:

- fast, convenient online submission

- thorough peer review by experienced researchers in your field

- rapid publication on acceptance

- support for research data, including large and complex data types

- gold Open Access which fosters wider collaboration and increased citations

- maximum visibility for your research: over $100 \mathrm{M}$ website views per year

At BMC, research is always in progress.

Learn more biomedcentral.com/submissions 